\title{
Biological control of Phaseolus vulgaris and Pisum sativum root rot disease using Trichoderma species
}

\author{
Hammad Abdelwanees Ketta ${ }^{*^{*}}$ (1) and Omar Abd El-Raouf Hewedy ${ }^{2,3}$
}

\begin{abstract}
Background: Root rot pathogens reported to cause considerable losses in both the quality and productivity of common bean (Phaseolus vulgaris L.) and pea (Pisum sativum L.). It is an aggressive crop disease with detriment economic influence caused by Fusarium solani and Rhizoctonia solani among other soil-borne fungal pathogens. Destructive plant diseases such as root rot have been managed in the last decades using synthetic pesticides.

Main body: Seeking of economical and eco-friendly alternatives to combat aggressive soil-borne fungal pathogens that cause significant yield losses is urgently needed. Trichoderma emerged as promising antagonist that inhibits pathogens including those inducing root rot disease. Detailed studies for managing common bean and pea root rot disease using different Trichoderma species (T. harzianum, T. hamatum, T. viride, T. koningii, T. asperellum, T. atroviridae, T. lignorum, T. virens, T. longibrachiatum, T. cerinum, and T. album) were reported both in vitro and in vivo with promotion of plant growth and induction of systemic defense. The wide scale application of selected metabolites produced by Trichoderma spp. to induce host resistance and/or to promote crop yield, may represent a powerful tool for the implementation of integrated pest management strategies.

Conclusions: Biological management of common bean and pea root rot-inducing pathogens using various species of the Trichoderma fungus might have taken place during the recent years. Trichoderma species and their secondary metabolites are useful in the development of protection against root rot to bestow high-yielding common bean and pea crops.
\end{abstract}

Keywords: Phaseolus vulgaris, Pisum sativum, Root rot, Trichoderma spp., Secondary metabolites, Biological control

\section{Background}

Soil-borne fungal diseases which occurring worldwide can destroy agricultural crops and cause significant yield losses. Fungal pathogens are considered a potent cause of soil-borne plant diseases (Strange and Scott 2005) and more than 1200 fungal species were implicated in plant diseases or crop failure in various major crops (Consolo et al. 2012). The common bean (Phaseolus vulgaris L.) is considered a strategic crop, especially in South America, Africa, and Asia (Torres

\footnotetext{
* Correspondence: kettahammad@gmail.com

'Agricultural Botany Department, Plant Pathology Branch, Faculty of

Agriculture, Kafrelsheikh University, Kafrelsheikh 33516, Egypt

Full list of author information is available at the end of the article
}

et al. 2009). Common bean represents a great source of carbohydrates, proteins, minerals, vitamins, and fibers in the human diet (Brougthon et al. 2003). Common bean and the pea (Pisum sativum L.) plants are continually exposed to diverse root rot pathogens with main disease symptoms of reddish-brown lesions on the hypocotyl and tap roots, vascular discoloration, foliar chlorosis and wilt, and seedling death (Ronquillo-López et al. 2010). Root rot disease in different regions of the world may be caused by several fungal pathogens and fungal-like organisms including Fusarium solani, Rhizoctonia solani, Pythium spp., and Fusarium oxysporum (Ronquillo-López et al. 2010).

\section{Springer Open}

(- The Author(s). 2021 Open Access This article is licensed under a Creative Commons Attribution 4.0 International License, which permits use, sharing, adaptation, distribution and reproduction in any medium or format, as long as you give appropriate credit to the original author(s) and the source, provide a link to the Creative Commons licence, and indicate if changes were made. The images or other third party material in this article are included in the article's Creative Commons licence, unless indicated otherwise in a credit line to the material. If material is not included in the article's Creative Commons licence and your intended use is not permitted by statutory regulation or exceeds the permitted use, you will need to obtain permission directly from the copyright holder. To view a copy of this licence, visit http://creativecommons.org/licenses/by/4.0/. 
Fusarium solani is one of the most aggressive pathogens that limits the productivity of common bean and is considered the most damaging Fusarium species (Toghueo et al. 2016). In some developing countries, root rot disease caused by Fusarium can wipe out the entire crop (Ongom et al. 2012). Similarly, $R$. solani has the potential to reduce the productivity and cause severe damage up to $94 \%$ disease incidence in the susceptible varieties and $39 \%$ in the resistant cultivars, causing a reduction of the root system in length and weight (Farrag 2011). Additionally, root rot pathogens can interact and increase disease severity, e.g., Fusarium spp. and Rhizoctonia spp. can form a high synergistic relationship on bean plants. F. solani is known to form thick-walled chlamydospores that can survive in soil in the absence of a host plant. Also, $R$. solani survives in soil for a long time through formation of sclerotia or fungal mycelium.

Various methods have been examined to manage root rot, particularly fungicide application (Al-Askar and Rashad 2010). However, abuse of these compounds can cause inhibition of pollinators, and beneficial soil microbial communities, and the emergence of fungicideresistant pathogens. Additionally, the accumulation of these toxic compounds has detrimental effects on human health and the environment. Disease management using biocontrol agents represents a potential alternative to synthetic fungicides and some of the most promising biocontrol agents belong to the genera Trichoderma. They have a variety of mechanisms to colonize various ecological niches through a broad antagonist spectrum, antibiotic, and mycoparasitism activity, and promote plant growth (Benítez et al. 2004). Trichoderma-based formulations are the most successful bio-fungicides used in integrated pest management, with more than $60 \%$ of the registered bio-fungicides based on Trichoderma species (Verma et al. 2007). They are currently used as commercial biological control agents against fungal and fungal-like root rot pathogens such as $R$. solani, Pythium spp., and Fusarium spp. (Saba et al. 2012). Several studies investigated the antagonistic activity of Trichoderma spp. against $F$. solani and $R$. solani to assess their efficacy as biocontrol agents and to elucidate their antagonistic mechanisms. Through various in vitro and in vivo assays, the antagonistic capacity with various mechanisms of Trichoderma spp. was explained (Fig. 1) including mycoparasitism (Fig. 2), induction of plant resistance, inhibitory metabolite production (antibiosis), plant growth stimulation, competition for nutrient and space, and production of lytic enzymes (Bastakoti et al. 2017). Their inhibition ability against root rot pathogens varied depended on both the specific Trichoderma species and pathogen (Singh et al. 2016).

This present review summarizes the recent studies that investigated the antagonistic ability of Trichoderma spp.

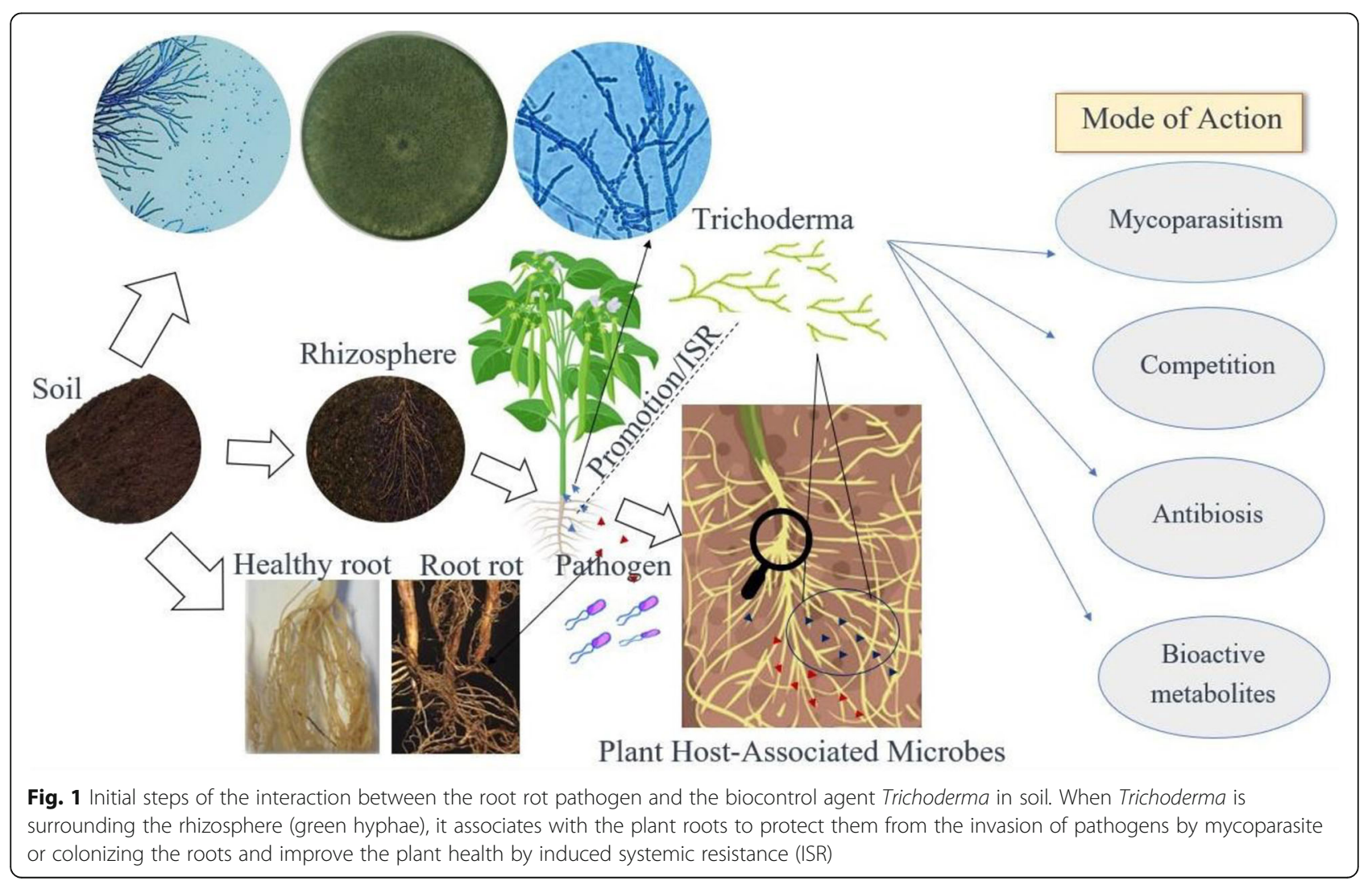



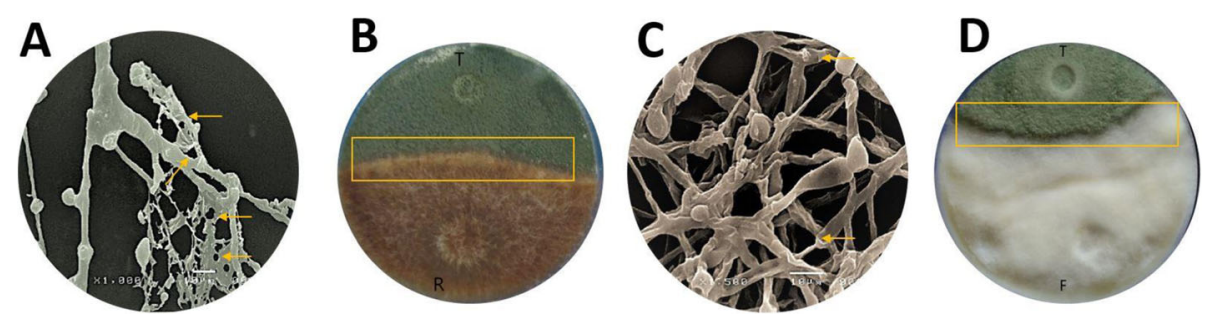

Fig. 2 Mycoparasitism of Trichoderma species: A SEM photomicrographs indicate the holes (yellow arrows) caused by the interaction between Trichoderma harzianum and root rot pathogen (Rhizoctonia solani) after 4 days of incubation, (magnification 500 x: bar $=10 \mu \mathrm{m}$ ). B Dual culture assay shows the T. harzianum interact with $R$. solani in vitro. C Hyphal interaction of Trichoderma asperellum and a root rot pathogen (Fusarium solani) after 5 days of incubation, yellow arrows show the coiling of hyphae (magnification $1000 \times$ : scale bar $=10 \mu m$ ). $\mathbf{D}$ Antagonism of $T$. asperellum strains against $F$. solani following a confrontation test

against fungal pathogens, particularly $F$. solani and $R$. solani that cause root rot disease in $P$. vulgaris and $P$. sativum crops. Moreover, describing the factors affecting Trichoderma efficiency. Finally, future prospects concerning the key factors needed for the development of reliable screening techniques for the prediction of biocontrol efficiency of a given isolate.

\section{Trichoderma species against Phaseolus vulgaris root rot disease}

Several studies investigated the antagonistic activity of Trichoderma spp. against $F$. solani and $R$. solani to assess their efficacy as biocontrol agents and to elucidate their antagonistic mechanisms through various in vitro and in vivo assays and in open field trials. In a greenhouse condition study, T. harzianum was applied as a biocontrol agent against $R$. solani via 2 methods of applications; simultaneous application with the pathogen; and 1 month before the pathogen inoculation. Recorded data indicated that $T$. harzianum could only suppress the root rot disease induced by $R$. solani in the preinoculation treatment with no effect on the disease in the simultaneous application. Findings reported by Nasir Hussein et al. (2018), showed that T. harzianum treatment reduced the disease severity up to $49 \%$ than the infected (untreated) control treatment. Moreover, bean plants treated with $T$. harzianum were improved in growth parameters in comparison with untreated plants. This study indicated that the timing application of treatment with $T$. harzianum may have a significant effect against $R$. solani. This pathogen aggressively attacked the hypocotyl part of the bean plant causing infection. $T$. harzianum colonization of the hypocotyl enhances the plant functions to suppress $R$. solani pathogen (Nasir Hussein et al. 2018).

In another interesting study, the biocontrol capacity of 3 Trichoderma species (T. asperellum, T. harzianum, and Trichoderma spp.) against $R$. solani was assessed both in vitro and in vivo experiments (Asad et al. 2014). Dual culture results showed that the 3 isolates inhibited
$R$. solani through parasitism, overgrowing the pathogen after 1 week of incubation. Also, water-soluble metabolites extracted from the tested isolates were high in antagonistic effect against $R$. solani, as shown with $T$. asperellum, which exhibited the highest rate of inhibition (74.4\%), followed by Trichoderma spp. (70.0\%) and T. harzianum (67.8\%). In the in vivo assay, Trichoderma species were applied at 7 days before and after the pathogen's inoculation. Bean plants treated with $T$. asperellum, 1 week before pathogen inoculation, had the highest relative biomass (127\%), followed by $T$. harzianum (126\%), 1 week after pathogen inoculation compared to the untreated healthy control (Asad et al. 2014).

From these results, it could be established that the timing of Trichoderma species application is an important factor that limiting the efficiency. Simultaneous application of Trichoderma species with the pathogen was not effective in comparison to 1 week or even 1 month before the pathogen inoculation. Furthermore, evaluating the efficiency of biocontrol agent $T$. harzianum against $R$. solani, in the greenhouse and open field trials was achieved by Matloob and Juber (2013). They found that $T$. harzianum exhibited a high antagonistic activity against $R$. solani and notable improvement of plant growth parameters and yield components. The greenhouse results showed that $T$. harzianum reduced disease incidence (31.2\%) and severity (18.8\%) of bean root rot than the infected control treatment $(R$. solani), $(100 \%)$ incidence and (80\%) severity, and increased fresh and dry weights ( 3.25 and $0.305 \mathrm{~g})$, than the infected control treatment ( $R$. solani) ( 1.36 and $0.162 \mathrm{~g}$ ). Besides, the field trials showed that $T$. harzianum reduced the incidence (50.0\%) and severity (26.8\%) of root rot than the infected control treatment (R. solani) (100 and 76.8\%) of disease incidence and severity, respectively. Significant increment in dry weight and yield (487.3 g and $1.83 \mathrm{~kg})$, respectively was also noted when $T$. harzianum was applied, in comparison to the infected control treatment (R. solani) (213.7 g and $0.61 \mathrm{~kg}$ ) of dry weight and yield, respectively. 
The great potential of $T$. harzianum as a biocontrol agent against $R$. solani was reported by Mayo et al. (2015) who evaluated the antagonistic ability of 23 Trichoderma isolates, using dual cultural technique and inhibitory metabolites assessment in vitro. The highest inhibition rate $(72.77 \%)$ in the confrontation assay was produced by T021 isolate. Additionally, 5 Trichoderma isolates (T003, T004, T006, T020, and T022) had a high inhibition rate $(86.7 \%)$. Fifteen Trichoderma isolates were selected based on the in vitro analysis to test in vivo against $R$. solani. Bean plants treated with isolate T019 alone had the highest growth, while the plants treated with both Trichoderma isolate T019 and $R$. solani had a similar growth to untreated plants. Trichoderma isolate T019 was identified, using internal transcribed spacer 1 (ITS1) sequence to be T. harzianum.

Another, T. harzianum isolate (RU01) was tested in vitro against $F$. solani, using the dual culture technique. Obtained results indicated that RU01 isolate inhibited the mycelial growth of $F$. solani through overgrowing after 3-4 days of incubation (Abeysinghe 2012). Surprisingly, F. solani was able to over grow the Trichoderma mycelia afterward. There was a reduction in conidia spore production than the control treatment. In a greenhouse experiment, disease parameters (lesion diameter and disease severity) were lower in treated seedlings than the infected (untreated) plants. It also promoted $P$. vulgaris growth by increasing both the length and weight of fresh root (Abeysinghe 2012). This study combined the in vitro and greenhouse application of T. harzianum RU01 to assess its antagonistic capacity and confirm its ability to combat root rot in common bean. The antagonistic activity of $T$. harzianum RU01 was explained by parasitism in this research.

Moreover, endophytic Trichoderma spp. were also reported to be used as biocontrol agents against soil-borne pathogenic fungi. Toghueo et al. (2016) isolated endophytic Trichoderma spp. from the bark of almond (Terminalia catappa) and the isolates with the highest potential of antagonistic effect against $F$. solani were identified through ITS-5.8S rRNA region sequencing as T. atroviridae and Trichoderma spp. The antagonistic activity of these 2 endophytes was evaluated in vitro. The results of the dual culture technique between $F$. solani and the 2 endophytes showed that $F$. solani was inhibited at $90 \%$ by $T$. atroviridae and $86.99 \%$ by Trichoderma species. T. atroviridae was more aggressive than Trichoderma spp. against $F$. solani in spore to spore confrontation assessment at (34.36 and 22.68\%) after $24 \mathrm{~h}$, respectively. Volatile compounds produced by both isolates had similar inhibition effect against F. solani, but the non-volatile components of $T$. atroviridae scored higher mycelial growth inhibition of F. solani than Trichoderma species. P. vulgaris seed germination was promoted to $100 \%$ in the first day of germination using $2 \times 10^{5}$ conidia/ml of $T$. atroviridae and promoted to $77.09 \%$ at $8 \times 10^{5}$ conidia $/ \mathrm{ml}$, in the presence of $F$. solani compared to $(57 \%)$ germination in the presence of $F$. solani alone. Bean seedling germinated from seeds treated with $T$. atroviridae had a lower disease severity and incidence (11.42 and 40\%), respectively, than the non-treated plants. This research interrupted the biocontrol ability of Trichoderma spp. with the established mechanisms from earlier studies (i.e., parasitism, nutrient and space competition, and antibiosis) and explored other modes of action related to non-volatile and volatile metabolites production. Obtained results of both in vitro and in vivo indicated that $T$. atroviridae, as a biocontrol agent, had a potential effect against $F$. solani.

In the open field experimental trials and in vitro assays, 4 Trichoderma species ( $T$. hamatum, T. harzianum, T. album, and T. viride) were investigated as biocontrol agents against $F$. solani and $R$. solani (AbdEl-Khair et al. 2010). Each of the previous Trichoderma species showed an antagonistic capacity in vitro, with $T$. hamatum that had the highest inhibitory effect (reducing mycelial growth) against both $R$. solani and $F$. solani. In the field application, common bean plants treated with $T$. album and T. viride had $0 \%$ of root rot. In addition, all the tested species induced defense responses than the control treatment. The inhibition effect against $R$. solani and F. solani may be due to the accumulation of enzymes such as chitinase, peroxidase, and polyphenol oxidase. So, accumulation and upregulation of antioxidant enzymes in the host plant might play an essential act in protection against pathogens (Ketta 2015). T. viride exhibited the highest activity of chitinase enzyme (430\%), followed by T. album (174\%), T. harzianum (150\%), and T. hamatum (132\%). However, T. harzianum increased the activity of polyphenol oxidase enzyme in bean plants (255\%), followed by $T$. viride (108\%), T. hamatum (103\%), and T. album (58\%). The range of peroxidase enzymatic activity was $26-124 \%$ with Trichoderma treatment application. Moreover, there was a positive correlation between the macroand micronutrients concentration and enzyme activity, i.e., chitinase, peroxidase, and polyphenol oxidase in the bean plants treated with all Trichoderma species which resulted in higher growth and yield parameters (Abd-El-Khair et al. 2010).

Several studies investigated the biocontrol ability of specific Trichoderma species against root rot fungal pathogens. One of the most studied Trichoderma species was $T$. harzianum, which showed an efficacy against $F$. solani and R. solani. A proteomic study of the effect of T. harzianum ALL 42, isolated from Brazilian soil, on growth promotion of $P$. vulgaris and inducing its defense mechanisms against $F$. solani and $R$. solani, was 
conducted to elucidate the molecular mechanisms responsible for these interactions (Pereira et al. 2014). T. harzianum ALL 42 promoted the agronomical parameters of bean plants. Bean plants treated with $T$. harzianum ALL 42 showed a differential expression pattern for defense response genes that encoded chitinase, glucanase, lipoxygenase, and peroxidase compared to untreated plants, as well as treated plants with $F$. solani or $R$. solani alone. In addition, T. harzianum ALL 42 increased plant resistance to $R$. solani as they increased defense response genes encoding peroxidase and glucanase compared to bean plants treated with $R$. solani alone. The proteomic analysis results indicated that 33, 22 , and $11 \%$ of the identified proteins related to metabolism, defense response, and oxidative stress response, respectively were found in the bean leaves. In addition, $17.2,24.1$, and $10.3 \%$ of the identified proteins related to metabolism, defense response, and oxidative stress response, respectively were found in the bean roots. This work aimed to elucidate the molecular mechanisms associated with inducing bean plant resistance and growth promotion when treated with $T$. harzianum ALL 42, but did not identify the exact main plant defense mechanism. However, the growth-promoting ability of $T$. harzianum ALL 42 was partially acting due to its ability to trigger expression of genes encoding defense responserelated enzymes. This expression was minimal for bean plants treated with T. harzianum ALL 42 and F. solani. This study showed the higher ability of $T$. harzianum ALL 42 to promote the growth and induce the plant resistance in the presence of $R$. solani rather than $F$. solani (Keswani et al. 2014).

Another investigation achieved by Akrami et al. (2012) reported the protective effect of T. harzianum (T1) and $T$. asperellum (T2) individually and in combination in the bean seed pelleting against $F$. solani. It concluded that the reduction of root rot disease was (59.8\%) after adding both $T$. harzianum (T1) and T. asperellum (T2) with concentration $\left(3 \times 10^{8}\right.$ conidia/ml $)$ in $10 \%$ sugar suspension for seed pelleting. In contrast, the reduction rate was $53.5 \%$ after adding the above species in water suspension. Moreover, T. harzianum (T1) alone exhibited a high reduction of $53.4 \%$ than T. asperellum (T2), which scored (42.9\%) under concentration of $6 \times 10^{8}$ conidia/ml in $10 \%$ sugar and water suspension as well. Muriungi et al. (2013) evaluated the efficacy of T. viride and T. koningii against Fusarium root rot of bean in vitro and in vivo. They investigated the sporulation ability of Trichoderma species on 3 types of carrier media (broken rice grains, vermiculite, and sorghum grains). In vitro studies showed that the inhibition percentage of Fusarium growth (1 week old after culturing) was closed to $100 \%$, when $T$. viride was applied using sprinkling or equidistant methods described by Dhingra and Sinclair (1986). In addition, a very poor growth of Fusarium, with $91 \%$ of growth reduction, was observed when $T$. koningii was applied using the same methods. In greenhouse trials, $T$. viride grown in broken rice grains exhibited $32 \%$ root rot severity, which was lower than the fungicide (metalaxyl 10\% + imidacloprid 10\% + carbendazim 10\%) and un-infested control treatment. Similarly, T. koningii grown in broken rice grains resulted in (56\%) severity (moderate) with non-differences with the fungicide. Interestingly, broken rice grain medium was the most effective one for both growth and survival of Trichoderma (spore concentration per gram of carrier) determined after 18 days of both $T$. viride and T. koningii with $\left(2.5 \times 10^{7}\right.$ and $1.4 \times 10^{7}$ conidia/g), respectively. From these results, it could be recommended that, adding of $10 \%$ sugar during the preparation of Trichoderma suspension for bean seed pelleting against $F$. solani increases the inhibition rate compared to water suspension. Moreover, carrier media are used for Trichoderma growth playing an important role in the improvement of its sporulation ability and consequently its efficacy against pathogenic fungi. So, the factors affecting Trichoderma efficiency could be concluded here as follows: (1) Timing of application (before or after the inoculation process of pathogenic fungus), (2) adding of carbohydrate source (10\% sugar) during the preparation of Trichoderma suspension for bean seed pelleting is more effective that water suspension, and (3) using of broken rice grains carrier media for Trichoderma growth plays an important role in the improvement of its sporulation ability and consequently its efficacy against pathogenic fungi.

The field application of bio-fungicides alone in management of soil-borne fungal pathogens is not highly effective. Hence, combinations of bio- and synthetic fungicides alternatively could be effective against the fungal pathogens with reduction amount of the fungicide applied. For instance, the combination of T. harzianum with methyl bromide fumigant in reduced amount under field application was achieved by Barakat (2002) who found that the combination reduced the incidence of bean root rot and damping-off caused by $R$. solani. The study concluded that using either $T$. harzianum alone or methyl bromide in reduced amount was not highly effective in disease management of bean plants. An increment in vegetative parameters, fresh and dry weight and yield components were found with a sub-lethal dose of methyl bromide combined with $T$. harzianum. Yield components increased by $75 \%$, when $T$. harzianum was combined with a reduced dose of methyl bromide compared to the control treatment, which was close to the full dose of the fumigant. Unfortunately, field application of Trichoderma spp. in management of soil-borne fungal pathogens is limited and not highly effective. 


\section{Trichoderma species against Pisum sativum root rot disease}

Another common and valuable food source for millions of people worldwide is pea (Pisum sativum L.), the essential leguminous crop for both local consumptions as well as exportation. Although the high-yielding cultivars are produced, the average seed yield per unit is still insufficient due to the infection with many diseases (Hamid et al. 2012). Pea root rot and damping-off diseases caused by soil-borne pathogenic fungi, such as $F$. solani and $R$. solani, are the most severe seedling diseases that cause substantial losses, either in seed quality or in yield. Hamid et al. (2012) studied the efficiency assessment of T. harzianum, T. viride, Pseudomonas fluorescens, and Gliocladium virens against $F$. solani. In vitro results indicated that $T$. harzianum exhibited the highest inhibition percentage in dual culture investigation (78.60\%), followed by T. viride $(75.72 \%)$, G. virens (69.52\%), and P. fluorescens (68.37\%). In pot experiments, $T$. harzianum reduced the disease incidence and severity (21.30 and 10.94\%), respectively, followed by $T$. viride (25.30 and 12.02\%), P. fluorescens (29.28 and $14.98 \%)$, G. virens (38.64 and $17.58 \%$ ), than the fungicide carbendazim 50 WP (14.64 and 4.98\%). No difference occurred between $T$. harzianum and carbendazim in seed germination percentage (90.00 and $90.00 \%)$, and number of days needed for seed germination (7.26 \pm 0.07 and $7.34 \pm 0.10$ ), respectively, followed by $T$. viride (86.00\% and $7.32 \pm 0.13)$, P. fluorescens $(83.00 \%$ and 7.37 $\pm 0.08)$, G. virens $(82.00 \%$ and $7.53 \pm 0.08)$, than the control treatment $(61.00 \%$ and $7.88 \pm 0.08)$.

The efficacy of T. harzianum, T. viride, G. virens, and $P$. fluorescens on managing of pea root rot disease, caused by $F$. solani was evaluated by Mudasar et al. (2012). In field trials, T. harzianum reduced disease severity percentages $(63.81 \%)$, followed by $T$. viride (60.44\%), P. fluorescens (51.19\%), G. virens $(41.82 \%)$ than the fungicide carbendazim 50 WP $(82.42 \%)$. No difference occurred between $T$. harzianum and the fungicide in seed germination percentage (80.00 and $80.00 \%)$, as well as the number of days needed for seed germination $(6.92 \pm 0.05$ and $7.01 \pm 0.08)$, respectively, followed by T. viride $(75.00 \%$ and $6.94 \pm 0.08)$, P. fluorescent $(73.00 \%$ and $6.98 \pm 0.07)$ and G. virens $(70.00 \%$ and $6.98 \pm 0.07)$, than the control treatment $(59.00 \%$ and $7.21 \pm 0.06)$.

Evaluation of seed treatment was investigated as well as soil application of T. koningii SMA-7 (Bio-1), RMA-8 (Bio-II), and JMA-11 (Bio-III), and T. harzianum SMA-4 (Bio-IV) by Kapoor et al. (2006). These treatments were mixed with farmyard manure against $F$. solani. In vitro investigations established that the maximum mycelial growth inhibition of $F$. solani was recorded $(82.16 \%)$ with $T$. harzianum SMA-4 (Bio-IV), followed by $T$. koningii JMA-11 (Bio-III) at $80.60 \%$, RMA-8 (Bio-II) at
75.19\%, whereas SMA-7 (Bio-1) at 70.53\%. In addition, they investigated the 4 bioagents of Trichoderma, in the form of soil and seed applications against $F$. solani under open field conditions. The most effective bioagent, through soil application, was T. koningii SMA-7 (Bio-1), which exhibited the least infection rate $(3.46 \%)$ of root rot-wilt complex, followed by $T$. harzianum SMA-4 (Bio-IV) with 3.63\%, T. koningii RMA-8 (Bio-II) with 9.49\%, and T. koningii JMA-11 (Bio-III) with 23.13\% than the control treatment (32.50\%). Furthermore, the used bioagents were less effective through seed application than using a soil application. T. koningii RMA-8 (Bio-II) scored the least disease incidence $(19.11 \%)$ of root rot-wilt complex, followed by $T$. koningii JMA-11 (Bio-III) with 25.03\%, T. harzianum SMA-7 (Bio-1) with $31.62 \%$, T. koningii SMA-4 (Bio-IV) with $33.97 \%$ compared to control treatment (32.50\%).

Another important point, the efficiency of seed priming (polyethylene glycol-PEG-8000 in ration $30.2 \mathrm{~g} / 100$ $\mathrm{ml}$ ), seed dressing (fungicide Rizolex-T 50\% WP at a recommended dose of $3 \mathrm{~g} / \mathrm{kg}$ seeds), and seed coating [seeds were immersed in $1 \%$ carboxymethylcellulose (CMC) for $30 \mathrm{~min}$, then coated with an individual suspension $\left(10^{7} \mathrm{CFU} / \mathrm{ml}\right)$ of Bacillus subtilis, Pseudomonas fluorescence and $3 \times 10^{4}$ conidia/ml of $T$. harzianum]. Then, seed bio-priming (spore suspension of T. harzianum, as well as bacterial suspension of B. subtilis, $P$. fluorescence supplemented with $1 \%$ CMC solution, against pea root rot disease induced by $R$. solani, $F$. solani, F. oxysporum, Sclerotium rolfsii, and Pythium spp. Furthermore, plant growth and crop yield, under greenhouse and open field conditions, were examined during the 2 growing seasons 2005/06 and 2006/07 by El-Mohamedy and Abd El-Baky (2008). Interestingly, the results of greenhouse experiment indicated that the incidence of disease, at pre-emergence (15 days after sowing) and root rot (45 days after sowing), was suppressed by all types of seed treatments. Seed bio-priming with $T$. harzianum reduced the pre-emergence damping-off 15 days after sowing by $F$. solani $(58.8 \%), R$. solani (50\%), and $S$. rolfsii (50\%), followed by seed coating treatment, F. solani (29.4\%), R. solani (30\%), and S. rolfsii (28.5\%), than the control treatment with a reduction $0 \%$ of all pathogens. The same trend was observed when applying the bio-priming seed treatment, which resulted in a reduction of F. solani, R. solani, and S. rolfsii, after 45 days from sowing, followed by seed coating treatment. Moreover, the results obtained from the field experiment showed that the disease incidence, in the pre-emergence (15 days after sowing) and root rot (45 and 60 days after sowing), was eliminated by types of seed treatments used over 2 seasons 2005/06 and 2006/07. In the first season 2005/06, seed bio-priming with T. harzianum resulted in a decrease in disease incidence, in the pre-emergence 
damping-off 15 days after sowing) with all pathogens (72.8\%), root rot after 45 days $(72.2 \%)$, and root rot after 60 days $(67.6 \%)$, followed by seed coating treatment with $48.4,46.3$, and $43.2 \%$, respectively, than the control treatment with $0 \%$ reduction in all stages. The same trend was observed during the following season 2006/07 when the bio-priming seed treatment resulted in the highest efficacy, followed by seed coating treatment. Moreover, during both seasons, bio-priming followed by seed coating with $T$. harzianum treatments stimulated plant height, the average number of leaves/plant, the average number of branches/plant and dry weight of shoots/plant, as well as yield improvement, i.e., the average number of pods/plants, average pod weight/plant and total yield of pea plants than the control treatment.

El-abd et al. (2013) studied the effect of biological seed treatments, such as priming with $1 \%$ carboxymethylcellulose, seed coating with $\left(3 \times 10^{6}\right.$ conidia/ml $)$ of $T$. harzianum, and bio-priming $1 \%$ CMC mixed with $\left(3 \times 10^{6}\right.$ conidia/ml) of $T$. harzianum, against pea root rot and damping-off diseases, growth and yield of plants under different concentrations of phosphorus fertilization (0, 25, 50, and $75 \mathrm{~kg} \mathrm{P}_{2} \mathrm{O}_{5} /$ feddan) (feddan $=4200 \mathrm{~m}^{2}$ ). The results of pre-emergence damping-off percentages indicated that the usage of bio-priming 1\% CMC mixed with $\left(3 \times 10^{6}\right.$ conidia/ml $)$ of $T$. harzianum, reduced the disease incidence to $4 \%$, followed by seed coating and priming treatments with no differences with phosphorus amount (50 or $75 \mathrm{~kg} \mathrm{P}_{2} \mathrm{O}_{5}$ ). A similar trend was obtained by root rot incidence. Disease reduction was achieved when seed bio-priming 1\% CMC mixed with (3 $\times 10^{6}$ conidia/ml) of $T$. harzianum treatment with $(75$ $\mathrm{kg} /$ fed $\mathrm{P}_{2} \mathrm{O}_{5}$ ). This treatment reduced post-emergence pea root rot to $4.25 \%$ after 40 days, and to $3 \%$ after 60 days. The second effective treatment was seed coating, followed by seed priming. These results indicate that the general increase in vegetative growth and yield, such as plant height, number of leaves/plant, fresh weight of leaves, pod yield, and green seed TSS with both increased levels of phosphorus fertilization and biopriming $1 \% \mathrm{CMC}$, mixed with $3 \times 10^{6}$ conidia/ml of $T$. harzianum treatment was a direct result of the $T$. harzianum ability to management root rot disease and increase root mass.

Evaluation of different leaf extracts, chemicals, and 2 Trichoderma species ( $T$. harzianum and $T$. viride), against the root rot of pea in a field trial, was investigated by Singh et al. (2014). T. harzianum and T. viride treatments were highly effective in reducing the root rot disease incidence with 18.94 and $19.52 \%$, respectively, followed by drek (neem) Melia azadirachta seed extract (21.00\%) and drek (neem) leaf extract (25.37\%). All treatments were compared to fungicides carbendazim and (metalaxyl and mancozeb) as well as the control treatment which scored root rot disease incidence (9.55, 8.56, and 38.96\%), respectively. T. harzianum and T. viride improved plant height, the number of branches/ plants, pod weight, the number of pods/plant, pod length, the number of grains/pod, and yield/ha. However, drek (neem) seed and leaf extracts were found to enhance growth and yield parameters, compared to the fungicides carbendazim and (metalaxyl and mancozeb) and control treatment.

Combination of Trichoderma species with beneficial bacteria such as P. fluorescens, Rhizobium sp., and $B$. subtilis under open field and greenhouse conditions was studied. Negi et al. (2014) evaluated the effects of pea seed treatment with $T$. harzianum and $T$. virens, individually or in combination with $P$. fluorescens, against $R$. solani and F. solani under field conditions. They found that $T$. harzianum reduced root rot disease severity in combination with $P$. fluorescens. The combination between T. harzianum and P. fluorescens as seed biopriming recorded the least disease severity (20\%), followed by $T$. harzianum $+P$. fluorescens $+T$. virens (30\%), P. fluorescens (31.1\%) than the untreated control treatment (49.4\%). In addition, the combination of $T$. harzianum with $P$. fluorescens had a remarkable increase in planta, for instance, germination percentage, shoot, root and seedling lengths, vigor index, number of pods/ plant, pod weight, number of grains/pod, and total yield/ ha were recorded. These investigations revealed that the combination of $T$. harzianum with $P$. fluorescens was the most effective treatment in reducing disease severity percentages and increasing plant growth parameters, as well as yield components compared to $T$. virens or $T$. harzianum treatment alone.

Trichoderma harzianum, Rhizobium sp., and B. subtilis were used as biological agents to manage pea root rot complex and improve plant growth parameters according to the study done by Muhanna et al. (2018). The results revealed that the root rot complex was caused by R. solani, F. oxysporum, Thielaviopsis basicola, and S. sclerotiorum. Field experiments indicated that all treatments decreased disease severity percentages. With $T$. harzianum at 50 and $100 \mathrm{ml}$ (concentration $3 \times 10^{7}$ conidia/ml), disease severity was decreased (15.1 and $13.8 \%)$ and (17.8 and 15.6\%), respectively, than the control treatment (22.2 and 20.5\%). Rhizobium sp., at (50 and $100 \mathrm{ml}$ ), reduced the disease severity (16.9 and $13.1 \%)$ and (17.8 and $14.2 \%)$, respectively, followed by treatments with B. subtilis (15.4 and 13.3\%) and (16.9 and $14.7 \%$ ), than the control treatment. Obtained results showed that all the biocontrol agents increased the growth parameters when applied at $100 \mathrm{ml}$.

Rhizobium leguminosarum combined with Trichoderma lignorum, $T$. longibrachiatum, and $T$. koningii were used as biological agents against pea root rot 
complex and improved plant growth parameters according to the study of Ketta et al. (2021). Greenhouse experiments indicated that combination of $R$. leguminosarum with $T$. longibrachiatum reduced the post-emergence damping-off (6.67\%) and root rot (9.58\%) caused by $R$. solani. Survived plants, nitrogen fixation, and yield parameters were also increased. Treatment of $R$. leguminosarum combined with $T$. koningii against $F$. solani reduced the post-emergence damping-off $(6.67 \%)$ and root rot (13.06\%).

The outcomes of using beneficial microbes such as Trichoderma fungi for management of root rot in the bean and pea have benefits for the plant health and production. For instance, they suppress pathogens, promoting plant growth, improving the availability of nutrient uptake, such as iron, nitrogen, and phosphorus, and enhancing host capacity under stressful conditions in the rhizosphere. Besides, the different mode of action of Trichoderma that includes competition for nutrients and space in the colonization sites, antibiosis and stimulation of plant immunity, and defense mechanisms. Secondary metabolites (SMs) produced by Trichoderma species are considered to be one of the most effective bioactive molecules in the biological control strategies. Microorganisms and plants, mainly produce these natural compounds from different pathways derived from acetyl coenzyme A, or amino acids, which have many biological activities related to the survival functions of the organism, such as competitive as an antifungal activity and auxin production as a symbiotic relationship. Beneficial microorganisms such as Trichoderma species can produce bioactive molecules that can participate in the interactive process, between plants and their invaded pathogens, with consequences for crop production. Biocontrol agents belonging to Trichoderma genus are wellknown producers of SMs, i.e., mycotoxins, antibiotics, and pigments, which are suppressive compounds to soilborne pathogens or microbial competitors.

Beside the abovementioned recommendations for improvement of Trichoderma efficiency, soil application treatments are more effective than using a seed application. In case of seed application treatment, bio-priming was an effective treatment compared to seed priming and seed coating. The combination of Trichoderma species with beneficial bacteria such as P. fluorescens, Rhizobium sp., and B. subtilis is recommended.

\section{Future prospects}

The greatest challenge in the field of biocontrol management of soil-borne pathogenic fungi is to insure a truly beneficial effect for the environment. Although, Trichoderma species are considered as biocontrol agents in integrated plant disease management, their biocontrol potential is yet to be limited to laboratory experiments.
Moreover, information concerning its utilization is limited and not distributed among farmers. Finally, genetic engineering and molecular tools are needed for improvement of biocontrol agents (BCAs) to be used efficiently against a wide range of soil-borne plant pathogens.

\section{Conclusions}

This review focused on the biological management of common bean and pea root rot-inducing pathogens, i.e., R. solani and F. solani, using different species of the Trichoderma fungus. Several strains of Trichoderma have been already registered as commercial biological control agents and some are currently used against root rot fungal pathogens. The wide scale application of selected metabolites produced by Trichoderma spp. to induce host resistance and/or to promote crop yield is still limited because of their low effectiveness in disease management compared to synthetic pesticides, and their performance can be adversely affected by a wide range of biotic and abiotic agents. Therefore, studying the characteristics of Trichoderma species, their interactions with pathogen/plant and biocontrol mechanisms can enhance the capability of Trichoderma spp.

\section{Abbreviations control agents \\ Acknowledgements \\ Not applicable}

ITS: Internal transcribed spacer; rRNA: Ribosomal RNA;

CMC: Carboxymethylcellulose; SMs: Secondary metabolites; BCAs: Biological

\section{Authors' contributions}

$\mathrm{OAH}$ created the idea of the manuscript. HAK collected the literature and wrote the half of the manuscript. $\mathrm{OAH}$ collected the literature and wrote the second half of the manuscript. HAK and OAH revised the manuscript several times. HAK formatted the manuscript according to the journal guidelines. HAK is responsible for the correspondence. The authors read and approved the final manuscript.

\section{Funding}

This work was done without any supporting funds.

Availability of data and materials

Not applicable

\section{Declarations}

Ethics approval and consent to participate

Not applicable

Consent for publication

Not applicable

Competing interests

The authors declare that they have no competing interests.

\section{Author details}

${ }^{1}$ Agricultural Botany Department, Plant Pathology Branch, Faculty of Agriculture, Kafrelsheikh University, Kafrelsheikh 33516, Egypt. ²Department of Plant Agriculture, University of Guelph, 50 Stone Road East, Guelph, Ontario N1G 2W1, Canada. ${ }^{3}$ Department of Genetics, Faculty of Agriculture, Menoufia University, Shibin El-Kom, Egypt. 
Received: 5 March 2021 Accepted: 12 June 2021

Published online: 22 June 2021

\section{References}

Abd-El-Khair H, Khalifa RKM, Haggag KH (2010) Effect of Trichoderma species on damping-off diseases incidence, some plant enzymes activity and nutritional status of bean plants. J Am Sci 6:486-497

Abeysinghe S (2012) Biological control of Fusarium solani f. sp. phaseoli the causal agent of root rot of bean using Bacillus subtilis CA32 and Trichoderma harzianum RU01. Ruhuna J Sci 2

Akrami M, Sabzi M, Mehmandar FB, Khodadadi E (2012) Effect of seed treatment with Trichoderma harzianum and Trichoderma asperellum species for controlling Fusarium rot of common bean. Ann Biol Res 3(5):2187-2189

Al-Askar A, Rashad Y (2010) Arbuscular mycorrhizal fungi: a biocontrol agent against common. Plant Pathol J 9(1):31-38. https://doi.org/10.3923/ppj.201 0.31 .38

Asad SA, Ali N, Hameed A, Khan SA, Ahmad R, Bilal M, Shahzad M, Tabassum A (2014) Biocontrol efficacy of different isolates of Trichoderma against soil borne pathogen Rhizoctonia solani. Pol J Microbiol 63(1):95-103. https://doi. org/10.33073/pjm-2014-014

Barakat R (2002) Control of bean root rot caused by Rhizoctonia solani using Trichoderma harzianum in combination with methyl bromide. Bethlehem Univ J 21:27-37

Bastakoti S, Belbase S, Manandhar S, Arjyal C (2017) Trichoderma species as biocontrol agent against soil borne fungal pathogens. Nepal J Biotechnol 5(1):39-45. https://doi.org/10.3126/njb.v5i1.18492

Benítez T, Rincón AM, Limón MC, Codon AC (2004) Biocontrol mechanisms of Trichoderma strains. Int Microbiol 7:249-260

Brougthon W, Hernández G, Blair M, Beebe S, Gepts P, Vardeyleyden J (2003) Bean (Phaseolus sp.): model food legume. Plant Soil 252(1):55-128. https:// doi.org/10.1023/A:1024146710611

Consolo VF, Mónaco Cl, Cordo CA, Salerno GL (2012) Characterization of novel Trichoderma spp. isolates as a search for effective biocontrollers of fungal diseases of economically important crops in Argentina. World J Microbiol Biotechnol 28(4):1389-1398. https://doi.org/10.1007/s11274-011-0938-5

Dhingra OD, Sinclair JB (1986) Basic plant pathology methods. CRC Press, Inc, Boca Raton

El-abd SO, Zaki MF, El-Mohamedy RSR, Riad GS (2013) Improving growth, fresh pod yield and quality, and controlling root rot and damping-off of pea grown in sandy soil by integration effect of phosphorus fertilizer with biological seed treatments. Middle East J Agriculture Research 2(1):8-15

El-Mohamedy RSR, Abd El-Baky MMH (2008) Effect of seed treatment on control of root rot disease and improvement of growth and yield of pea plants. Mid East Russ J Plant Sci Biotechnol 2(2):84-90

Farrag AA (2011) Efficiency of different biocontol agents on both susceptible and resistant bean plants and their protein pattern consequences. J Am Sci 7:714

Hamid C, George D, Jones MW (2012) Management of root rot of pea (Pisum sativum L.) through bioagents. Afr J Microbiol Res 6(44):7156-7161

Kapoor AS, Paul YS, Singh A (2006) Integrated management of white rot and root rot - wilt disease complex of pea. Indian Phytopathol 59(4):467-474

Keswani C, Mishra S, Sarma BK, Singh SP, Singh HB (2014) Unraveling the efficient applications of secondary metabolites of various Trichoderma spp. Appl Microbiol Biotechnol 98(2):533-544. https://doi.org/10.1007/s00253-013-53445

Ketta HA (2015) The role of down-regulation of antioxidant enzyme activities and reactive oxygen species accumulation in playing an essential act in soybean susceptibility to Fusarium virguliforme infection. J Plant Protect Pathol Mansoura Univ 6(10):1439-1461. https://doi.org/10.21608/jppp.2015.75345

Ketta HA, El-Khateeb NM, Saleh MM, Kamel SM (2021) Efficiency assessment of combinations between Rhizobium leguminosarum and Trichoderma spp. for controlling of pea (Pisum sativum L.) damping-off disease. Egypt J Phytopathol 49(1):1-14. https://doi.org/10.21608/ejp.2020.43495.1007

Matloob HA, Juber SK (2013) Biological control of bean root rot disease caused by Rhizoctonia solani under green house and field conditions. Agric Biol J N Am 4(5):512-519

Mayo S, Gutierrez S, Malmierca MG, LorenzanaA CMP, Hermosa R, Casquero PA (2015) Influence of Rhizoctonia solani and Trichoderma spp. in growth of bean (Phaseolus vulgaris L) and in the induction of plant defense-related genes. Front Plant Sci 6:685
Mudasar A, Vaseem R, Parvaiz A, Gazala R (2012) Bio-management of root rot of pea (Pisum sativum L.) caused by Fusarium solani f. sp. pisi. Int J Curr Res 4(10):017-020

Muhanna NAS, Elwan SE, Dib ND (2018) Biological control of root rot complex of pea (Pisum sativum L.). Egypt J Phytopathol 46(1):49-67. https://doi.org/10.21 608/ejp.2018.87766

Muriungi JS, Mutitu EW, Siboe MG (2013) Biocontrol of Fusarium root rot in beans by antagonistic Trichoderma fungi. Int J Agri Sci 3(7):550-557

Nasir Hussein A, Abbasi S, Sharifi R, Jamali S (2018) The effect of biocontrol agents consortia against Rhizoctonia root rot of common bean Phaseolus vulgaris. J Crop Protect 7:73-85

Negi DS, Sharma PK, Gupta RK (2014) Management of root-rot complex disease and assessment of plant growth promoting characters in vegetable pea with native and commercial antagonistics through seed biopriming. Int J Recent Scientif Res 5(8):1416-1421

Ongom P, Rubaihayo P, Nkalubo S, Gibson P, Chanda R, Mungoma C, Osiru D, Mwala M, Mwansa K, Majengo C (2012) Inheritance of resistance to Fusarium root rot in three common bean genotypes. Electron J Plant Breed 3:892-897

Pereira JL, Queiroz RM, Charneau SO, Felix CR, Ricart CA, da Silva FL, Steindorff AS, Ulhoa CJ, Noronha EF (2014) Analysis of Phaseolus vulgaris response to its association with Trichoderma harzianum (ALL-42) in the presence or absence of the phytopathogenic fungi Rhizoctonia solani and Fusarium solani. PLoS One 9(5):e98234. https://doi.org/10.1371/journal.pone.0098234

Ronquillo-López M, Grau C, Nienhuis J (2010) Variation in reaction to Fusarium spp. identified in a common bean (Phaseolus vulgaris L.) population developed for field-based resistance to root rot and wilt. Crop Sci 50(6): 2303-2309. https://doi.org/10.2135/cropsci2010.02.0099

Saba H, Vibhash D, Manisha M, Prashant K, Farhan H, Tauseef A (2012) Trichoderma-a promising plant growth stimulator and biocontrol agent. Mycosphere 3(4):524-531. https://doi.org/10.5943/mycosphere/3/4/14

Singh AK, Sharma V, Singh AK, Singh VK (2014) Effect of leaf extracts, fungicides and bio-agents against root rot of pea (Pisum sativum L.). Res Crops 15(3): 651-654. https://doi.org/10.5958/2348-7542.2014.01391.6

Singh V, Upadhyay RS, Sarma BK, Singh HB (2016) Trichoderma asperellum spore dose depended modulation of plant growth in vegetable crops. Microbiol Res 193:74-86. https://doi.org/10.1016/j.micres.2016.09.002

Strange RN, Scott PR (2005) Plant disease: a threat to global food security. Ann Rev Phytopathol 43(1):83-116. https://doi.org/10.1146/annurev.phyto.43.113 004.133839

Toghueo RMK, Eke P, Zabalgogeazcoa Í, de Aldana BRV, Nana LW, Boyom FF (2016) Biocontrol and growth enhancement potential of two endophytic Trichoderma spp. from Terminalia catappa against the causative agent of Common Bean Root Rot (Fusarium solani). Biol Control 96:8-20. https://doi. org/10.1016/j.biocontrol.2016.01.008

Torres AR, Cursino L, Muro-Abad Jl, Gomes EA, Araújo EF, Hungria M, Cassini STA (2009) Genetic diversity of indigenous common bean (Phaseolus vulgaris L.) rhizobia from the state of Minas Gerais, Brazil. Braz J Microbiol 40(4):852-856. https://doi.org/10.1590/S1517-83822009000400016

Verma M, Brar SK, Tyagi RD, Surampalli RY, Valero JR (2007) Antagonistic fungi, Trichoderma spp.: panoply of biological control. Biochem Eng J 37(1):1-20. https://doi.org/10.1016/j.bej.2007.05.012

\section{Publisher's Note}

Springer Nature remains neutral with regard to jurisdictional claims in published maps and institutional affiliations. 